\title{
Narrative in nursing research: An overview of three approaches
}

Briege Casey, Denise Proudfoot, Melissa Corbally, School of Nursing and Human Sciences, Dublin City University

\begin{abstract}
Aim: The aim of this paper is to present and discuss three popular narrative research approaches which have been successfully used by the authors in nursing research. Examples of each approach are offered to illustrate potential application in health care contexts.

Background: The creation, function and interpretation of narratives are of increasing interest to nurse researchers worldwide. Currently a variety of narrative research approaches are used to explore how people make sense of experience. While this diversity adds to the richness and scope of the methodology, practitioners new to narrative research may struggle in determining which approach best suits their research purposes and contexts.
\end{abstract}

Design: This discussion paper presents the philosophical basis, methodology, strengths and challenges of the following three commonly used narrative approaches: Murray's Narrative Framework, the Biographical Narrative Interpretive Method and Arts-Based Narrative Methods.

Data sources: Data sources dating from 1934-2014 were used. These included seminal texts as well as articles from nursing and social science journals on narrative and narrative research found in the CINAHL, Medline and PsycInfo databases.

Implications for nursing: This discussion offers clarity and guidance to nurse researchers who are considering/ using narrative research methods to inquire into the storied nature of human experience and sense making processes. 
Conclusions: Employing a specific narrative research approach requires close attention to the 'fit' of the research question/context with the particular method under consideration. Whilst sharing some narrative commonalities, each of these three methods enables the emergence of unique analytic and interpretive perspectives regarding stories relevant to nursing practice.

Keywords: nursing research, narrative methods, Murray's narrative framework, biographical narrative interpretive method, arts-based narrative methods, research exemplars 


\section{SUMMARY STATEMENT}

\section{Why is this research or review needed?}

- Narrative research is a method of inquiry that is of growing relevance and value for nursing knowledge and practice.

- A variety of narrative approaches exist, which can result in methodological confusion. Therefore greater understanding is required in nursing research regarding the affordances and uses of a range of narrative research approaches.

- The three narrative methods discussed; Murray's Narrative Framework, the Biographical Narrative Interpretive Method and Arts-Based Narrative Inquiry exemplify a commonly used and varied range of narrative research practice.

\section{What are the key findings?}

- Whilst sharing some narrative commonalities, each of the three methods outlined in the paper enables the emergence of unique analytic and interpretive perspectives regarding stories encountered in nursing practice.

- Employing a specific narrative research approach requires close attention to the 'fit' of the research question/context with the particular method under consideration.

- The three narrative approaches presented in this paper confirm the usefulness and richness of this research methodology for nurse researchers wishing to inquire into the storied nature of human experience and sense making.

\section{How should the findings be used to influence policy/practice/research/education?}

- The findings will increase awareness of the important function of narrative processes in enabling patients and practitioners to make sense of complex and often traumatic life 
experiences. This heightened awareness should inform policy, practice, research and education

- Nurse researchers should familiarise themselves with the affordances and practices of various narrative research approaches and engage confidently with a range of narrative inquiry methods. 


\section{INTRODUCTION}

Nursing is largely an oral narrative culture (Sandelowski 1994, Wolf 2008, Adamski et al. 2009). We are immersed in stories; our own nursing stories and the stories of people in our care. We order our life experiences into stories with temporal and logical sequences and this narrative mode of thinking helps us to organise and make sense of disparate life events (Bruner 1990). This narrativizing process is invariably employed to re-configure experiences of illness and trauma (Frank 1995, White 2004, Williams 2009).

In healthcare contexts internationally, stories about illness and caring are shared at shift handovers, at bedsides, in corridors, offices, cars and staff rooms. McAllister et al.. (2009 p157) claim that in the sharing, narratives of illness and caring have communicative, sense-making and transformative potential and that 'these benefits are crucial for an applied profession such as nursing'. Many contemporary nurse researchers, including Holloway and Freshwater (2007) and Gregory (2010) argue that the phenomenological insights generated through the analysis and sharing of narratives advance nursing knowledge and research practice. Narrative research in nursing has flourished in recent years and there has been a corresponding proliferation in approaches to understanding and exploring storied accounts. McCance et al. (2001) propose that nurse researchers new to narrative approaches can experience some confusion as to the selection and use of particular methods to suit their purposes. This paper presents a broad overview of the main philosophical foundations underpinning narrative research and offers examples of three narrative approaches used by the authors which reflect this range of theoretical positions. Common features and unique characteristics across these approaches are described with the aim of informing potential narrative researchers in their choices of appropriate narrative methods to suit specific research questions and 
contexts. We will begin by discussing some of the common overarching premises of narrative research

\section{Background}

Narrative research encompasses a broad range of approaches which are focused on gathering, analysing and presenting storied texts or personal accounts with the purpose of establishing a rich description of the meaning of an individual's experience (Riessman 2008). Exploration of narrative generally embraces one of the following two main positions, however it is important to note that these are not perceived as mutually exclusive and elements of both can be found in various studies.

Position 1: Narrative is a human sense-making process which is essential for configuring lived experience

This position owes much to three philosophical origins: the first is phenomenology which is concerned with meanings of lived experience as encountered from the subjective or first person point of view (Van Manen 1997, Merleau-Ponty 1999). The second is cognitive psychology, particularly the work of Bruner (1990) and Sarbin (1986) who regard narrative sense-making as an integral component of configuring often complex life experiences. The third philosophical origin is social constructivism (Vygotsky 1978); the belief that meaning is created in the individual in the context of a social world. Articulated narrative is regarded as an expression of individual reality, however there is acknowledgement that narrative configuration is influenced by social contexts and through time. Using a naturalistic or realist approach, the narrative researcher is particularly concerned with the content and the 'what' of the story; what experiences participants 
have had and what those experiences have meant to them. These experience centred approaches (Patterson 2008) generally adopt a hermeneutic approach to analysis; the researcher moves back and forth between stories, developing themes and aiming at full interpretation and understanding. Examples of experience centred narrative approaches in nursing research include Overcash (2004) who explores the quality of life of older women with breast cancer and Law et al. (2015) who examine the experience of learning to speak up among newly graduated registered nurses. Later in this paper an example of an experience centred approach (Murray's Narrative Framework 2000, 2008) will be discussed in more depth.

Position 2: Narrative is a tool of social construction; reality and meaning are configured through telling and sharing stories using the medium of language

This position is influenced by postmodern and social constructionist thinking (Sparkes \& Smith (2008) Gregen (2009). Rather than viewing the process of construction of meaning as residing in the individual, social constructionists contend that meaning and reality are configured through social processes; through the performance and interpretations of stories in social domains. (Calvert 2014). According to this position, narratives also reveal much about social life or culture, as aspects of culture are conveyed through the story. Researchers using social constructionist approaches are more interested in the 'how' of the narrative; how the story has been configured and how it is communicated, how the account presents self and (life) story and how the personal story transmits wider social and cultural meanings. It follows then, that such a close examination of the narrative as product or text demands a highly structured analytic approach. Here, examination of language goes beyond its referential content and the researcher studies the use of particular modes of speech, 
metaphors and language that is nuanced by particular perspectives (Labov \& Waletzky 1967, 1997). An example of this structured approach is Wengraf's $(2001,2008)$ Biographical Narrative Interpretive Method (BNIM) which is discussed later in this paper. Recent studies by nurse researchers using structured approaches are MacLellan (2015), who uses Labovian analysis to explore childbirth stories on the internet and Ramvi (2015) who uses Wengraf's (2001, 2008) BNIM in a case study examining a nurse's self- understanding in the context of her professional practice.

The focus on the socially mediated nature of narrative is also influenced by poststructuralist concerns such as those of Foucault (1980), Blumenreich (2004), regarding the nature of knowledge and power in social contexts and how these forces are enacted through culturally agreed interpretations of narratives (grand narratives or meta-narratives). Poststructuralist narrative approaches explore the interaction between self and environment as we enact our narratives (Carolan 2005); there is increasing interest as to how personal and cultural narratives; (the personal and the political) interact and rub up against each other (Wilson \& Crowe 2009, Casey \& Gordon 2010). Poststructuralist thinking also highlights language as already embedded with pre-scribed, socially sanctioned meanings which require close attention and deconstruction (Taylor 2003). Given these perceived limits of language, poststructuralist approaches are interested in divergent ways of apprehending and communicating experience, for example the nature of embodied experience and the affordances/characteristics of arts-based narrative research (Stickley et al. 2007, Lapum et al. 2012). Arts-based approaches contain elements of both phenomenological and social constructionist philosophy; which Riessman (2008) terms the 'what' and the 'how' of narrative. There is interest in what the lived, embodied, personal experience feels like for the 
person and also a focus on how this experience is constituted by and in turn constitutes the social milieu. An example of arts-based narrative approach developed by Edgar (2004) will be discussed later in the paper.

\section{Data sources}

The CINAHL, Medline and PsycInfo databases were searched using terms relevant to the three methods under discussion. These terms were: nursing, narrative research, Murray's Narrative Framework, Arts-based Narrative Research and Biographical Narrative Interpretive Method. The terms narrative research and narrative inquiry were used as synonyms. This search, as expected delivered a large, often undifferentiated volume of research articles pertaining to narrative research. This was useful for some of the more general discussion regarding narrative research in nursing. A more intensive search by each author in relation to the three research methods discussed was also required and contemporary examples of these approaches were generated through this process. Seminal texts were also accessed as these illuminated the philosophical foundations of social constructivism, cognitive psychology, social constructionism and poststructuralism. Therefore material dated 1934-2014 was reviewed. This discussion paper is also informed by our own experiences as researchers using these methods

\section{DISCUSSION}

This paper considers three common narrative approaches, each of which exemplifies the premises of the philosophical positions discussed above. These are; an experienced centred narrative method i.e. Murray's Narrative Framework (Murray 2000, 2008), used by Proudfoot (2014), a 
structured narrative approach i.e The Biographical Narrative Interpretive Method (Wengraf 2001, 2008), used by Corbally (2011) and Arts-based Narrative Research with a particular focus on Imagework (Edgar 2004) used by Casey (2009). The aim of this discussion of exemplars is to share research experience by demonstrating how each approach facilitated the authors to explore and understand health experiences. It is further hoped that this discussion paper will provide clarity and guidance to nurse researchers considering/ using narrative research methods.

\section{Murray's Narrative framework}

\section{Background and theoretical/philosophical basis}

The first research approach, Murray's Narrative Framework (Murray 2000, 2008) is an experience centered narrative research method which aims to gain insight into the meanings of lived experiences. Squire (2008) posits that experience-based narrative research is based on the phenomenological assumption that through stories, experiences become part of consciousness. Narrative performs a transformative function enabling sense-making concerning a particular experience. Murray's narrative framework examines storied experiences focusing on four specific elements of the narratives; personal, interpersonal, positional and ideological (Murray 2000, 2008, Shelton \& Johnson 2006). The personal element is concerned with how an individual describes their own experience. The interpersonal and positional examine the interaction and power relations/positions between the participant and the interviewer and how the narrative evolves during the interview. Finally, the ideological element establishes how stories relate to cultural/societal contexts and identifies social representations in the narratives. The focus on the personal interpretation is common to all experience centred approaches as previously discussed. 
The interpersonal, positional and ideological explorations in Murray's Framework acknowledge the influence of dialogical and societal forces on interview context and story creation; however narrative sense-making is viewed as occurring in the consciousness of the individual. In nursing contexts this approach generally involves interviewing a small number of participants who share a lived experience for example; people living with the experience of chronic illness (McMahon et al. 2012).

\section{Methodology}

This approach employs semi-structured interview where the participant is asked to recount a story related to the topic of inquiry. The analysis of narratives adopts a hermeneutic approach using the four 'lenses' previously described; examining transcripts and identifying key events/experiences to gain understanding of personal experiences, the narrative tone and the narrators' use of imagery and metaphors. The interpersonal analysis explores how the accounts are co-constructed by the narrator and the researcher by examining conversation flow in the narrative while taking account of the interview context. The positional level extends the intrapersonal level to consider differences between the researcher and the narrator and how this influences the co-construction of the narratives. In health research, examining the positional level can be important if the balance of power lies with the health professional/researcher (McMahon et al. 2012) which can inhibit the narrator telling their story. The ideological level explores how the participant perceives their experiences in relation to broader socio cultural norms associated with their health condition for example, stigma and mental illness. 
The main strength of Murray's framework is that it enables in-depth exploration of personal lived experience as created and recounted through narrative. The hermeneutic analysis allows for the understanding of health and illness experiences from different perspectives through detailed exploration of the meaning in the collected stories. Murray's framework goes further than some other experience centered narrative approaches in that it also considers the effects of interaction with the social environment and co-construction on the creation and articulation of the narrative. There is an interest in the language and metaphor used in the narrative which also extends this method. Given that broader social processes affect many aspects of an individual's experiences of health and illness, this approach has much to offer nursing and healthcare research particularly when attempting to appreciate a person's experience of illness (Holloway \& Freshwater 2007).

In her critique of experience centered approaches, Squire (2008) argues that there is a tendency towards homogeneity (through fitting diverse and possibly contrasting experiences into themes and typologies) and researcher empiricism in that there are a priori expectations as to the format and content of experience stories and these expectations can guide the conduct of the research and analysis. Squire (2008) also contends that because of the unproblematic and dominant focus on experience, the significance of language can be overlooked and that this can contribute to misinterpretation of the related narratives. However Murray's analytic approach incorporates language features including metaphors and the tone of the narrative and this consideration reduces the possibility of misinterpretation of collected stories.

Use of Murray's narrative framework in health research 
Murray's narrative framework has informed a variety of health related studies, Shelton \& Johnson (2006) used this method when exploring mothers' subjective experiences of delayed motherhood. Murray's approach supported them in exploring how the women negotiated social expectations of mothering in their personal narratives. More recently, it was used in studies about the experiences of breast cancer (Murray 2009) and those living with fibromyalgia (McMahon et al. 2012) and provided insight into the multi-dimensional impact of these conditions which is useful to nurses involved in their care. Proudfoot (2014) drew on this framework in her doctoral research exploring the mothering experiences of HIV positive women. In this study, participants described significant events since diagnosis and this research revealed the complex interrelationships between mothering stories and HIV stories. For example, some mothers prioritised their children's care by deliberately minimising the negative aspects of being HIV positive; they invested more heavily in their mothering role. Using Murray's framework to analyse these narratives allowed for a broader understanding as to how being a mother influences the HIV experience and vice versa. Importantly, Vallido and colleagues (2010) argue that healthcare professionals (including nurses) rarely acknowledge the influence of being a mother on illness/treatment attitudes and behaviour; through using Murray's framework Proudfoot's (2014) study made visible this previously overlooked dimension of the women's experiences and narratives. Murray's experience centered narrative approach is an option for nurse researchers who are interested in lived health/illness experiences in a relational and social context. A more structured narrative approach is The Biographical Narrative Interpretive Method (BNIM) and the next section considers its use in health research.

\section{Biographical Narrative Interpretive Method (BNIM)}




\section{Background and theoretical/philosophical basis}

BNIM is concerned with the exploration of subjective experience in historical and social contexts and examines life narratives in a structured way. Through case based analysis BNIM facilitates systematic and retrospective exploration of the person's whole life story (Biography) and how they tell it (Narrative) whilst appreciating that narratives are subject to social and historical configuration and interpretation (Interpretive) (Wengraf 2008). BNIM follows social constructionist philosophy (Berger \& Luckmann 1966) concerning the social nature of knowledge and reality construction, regarding narrative as vehicle by which socially mediated knowledge becomes manifest. BNIM research is interested in the structure of the life narrative and how these historical and socially mediated meanings inscribe the narrative. Accordingly, close examination of language and text structure is an important component. The generation of case accounts using BNIM is characterised by a particular interview style and a comprehensive, formulaic analytic method. In addition to social constructionism, this method is informed by other theoretical orientations, including biographical approaches (Chamberlayne et al.. 2000), literary criticism/ linguistic analysis (Labov \& Waletzky 1967/1997) and grounded theory (Glaser \& Strauss 1968).

\section{Methodology}

BNIM in practice uses a unique interviewing technique to elicit an uninterrupted story from participants. This is called the Single Question Aimed at Inducing Narrative (SQUIN) (Wengraf 2001) and always underpins the first interview session. A typical example of a SQUIN is as follows: 'I would like you to tell me your life story, all the events and experiences which were important for you. Start wherever you like. Please take the time you need. I'll listen first I won't 
interrupt, I'll just take some notes for afterwards'. Up to two additional sub-sessions can follow depending on the nature of the research but any subsequent questions must relate to material arising from the SQUIN (Wengraf 2001).

The BNIM analytic strategy uses a structured approach to explore the individual's life history or life story (case). If BNIM is used to its full capacity, nine stages of analysis are used per case with a tenth stage comparing across cases (Jones 2001, Corbally \& O’Neill 2014). Typically sample sizes are small given the intensity of analysis. A more in depth discussion of the intricacies of BNIM can be found in (Corbally \& O'Neill 2014). There is also a very active online support network for BNIM users (https://www.jiscmail.ac.uk/cgi-bin/webadmin?A0=BIOGRAPHICNARRATIVE-BNIM [accessed $2^{\text {nd }}$ April 2015]. Here, Tom Wengraf (the champion of BNIM in the UK) and many others offer timely support for scholars using this method) which is useful. The following diagram outlines what is involved in the various stages of BNIM analysis (Figure 1 below). 
Figure 1: Stages of BNIM analysis

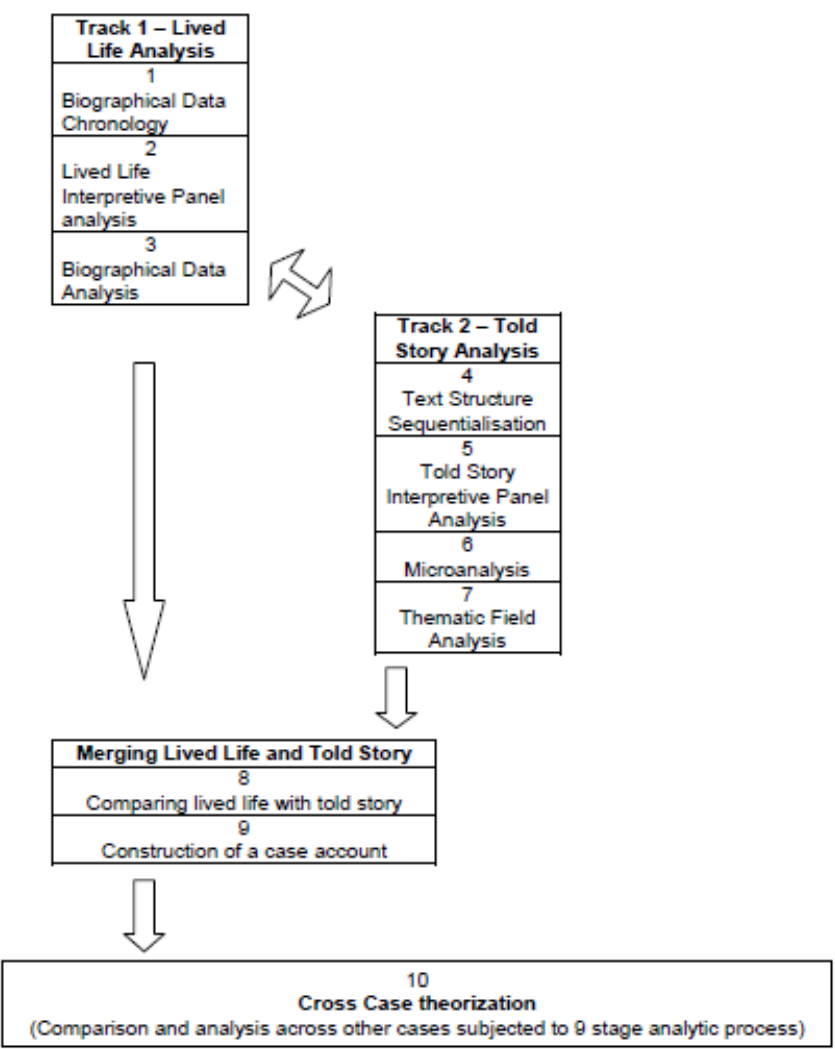

Strengths and challenges

The focus on participants' biographies allows nurse researchers to consider people as historically and socially formed actors whose actions are only fully intelligible in their historical and cultural contexts (Gubrium \& Holstein 2009, Gunaratnam \& Oliviere 2009). According to Lomas (2012) and Ofri (2015) the contemporary forces in nursing of bureaucracy and cost-effective healthcare management often render the individual life story invisible. BNIM acknowledges the processes of change, time, culture and history, as well as the lived texture of lives and the appreciation of structure and agency in those lives (Meares 2007). Case-based methods are particularly useful in discovering individualised reactions to life altering challenges such as serious illness, disability or as in the study undertaken by Corbally (2011), intimate partner violence. The formulaic structure 
of BNIM provides narrative researchers with a clear and rigorous structure to intensively analyse life stories from a small cohort of participants.

One of the challenges with BNIM and other highly structured narrative analysis approaches is that strict application of the formulaic approach can decontextualise narratives by ignoring interactional and contextual factors (Bornat 2008). In this approach, the influences of the research environment and researcher participant relationships/interactions are not considered, yet according to Atkinson and Silverman (1997), these elements can also influence story formulation.

The specific interviewing and analysis processes involved in BNIM demands some level of skill and training on behalf of the researcher. Jones (2003) also contends that using the full rigour inherent in the 'classic' BNIM method may result in excessive and/or overly complex data generation and analysis processes depending on the phenomenon of study. Although Corbally (2011) used all ten stages of the 'classic' BNIM method, it can be modified to incorporate less analytic stages depending on the nature of the research question (O’Neill 2011).

\section{Use of BNIM in health research}

BNIM has been used in a variety of health research projects. For example O'Neill (2011) studied end of life care decisions about older people in hospitals, Nicholson et al. (2013) examined older persons' narratives regarding frailty and Garrat (2014) explored the working lives of independent midwives and their perceptions of the mother-midwife relationship. Corbally (2011) used the classic BNIM approach in examining men's stories of female perpetrated intimate partner violence (IPV). IPV is mostly understood as a problem experienced by women. Therefore men who are being abused by women frequently feel that their abuse experiences are 'unbelievable' Corbally 
(2011). BNIM enabled exploration of the tensions between the men's lived lives and their told stories of abuse and how the context of their lives as men in a patriarchal society made it very difficult for them to make sense of their experiences of IPV. This approach also proved useful in creating contextual interpretive case accounts and in highlighting particular narrative strategies men used to talk about IPV. Another narrative informed research method that is concerned with silenced stories is Arts-based Narrative Research and this method is discussed in the next section.

\section{Arts-based Narrative Research}

\section{Background and theoretical/philosophical basis}

Arts-based Narrative Research is an umbrella term referring to approaches which employ some art form as part of the narrative research inquiry (Finley, 2011). In health research contexts, a range of arts-based practices - visual (video, photography and painting), performative (drama, dance and music) or literary (poetry, fiction) are used to facilitate divergent ways of inquiry, meaning making and representation of narratives (Leavy 2009). Some contemporary writers (Rogers 2007, Schick Makaroff et al. 2013) have highlighted the limits of language in communicating the 'unsayable'; that is experiences, particularly of trauma, that are beyond language and thus difficult to narrate. Frosh (2004) and Leitch (2006) posit that arts-based research extends traditional practices of narrative inquiry in that it retains the conceptual framework concerning the narrative mode of configuring experience, but goes beyond the limits of language or prosaic consciousness through the use of arts-based methods that give access and expression to embodied, 'felt' knowing. Thus engagement with narrative shifts from the story as received and interpreted to the story as created and/or performed. In the process of creating and performing, tentative, ambivalent and previously unvoiced perceptions and meanings are grappled with and 
articulated in evocative ways (Barone and Eisner 2012). Philosophies influencing arts-based narrative research straddle phenomenology (Gadamer 1989), aesthetics/art as experience (Dewey 1934), social constructionism (Gregen \& Gregen 2012) and poststructuralism (Foucault 1972); there is interest in both the internal, individual narrative configuration of experience (often embodied) as well as habitually performed, socially inscribed narratives.

\section{Methodology}

Arts-based Narrative Research may involve the use of any art form(s) at any point in the research process, whether for generating, interpreting and/or communicating knowledge (Knowles \& Cole 2008). Additionally, arts-based methods may be combined with more traditional research approaches at any stage of the research process. For example, Wright (2006) and Lapum et al. (2013) gathered data on healthcare issues through participant poetic writing and analysed the poems using traditional thematic analysis and textual discussion. Alternatively, Edwards (2015) incorporated poetry at a later stage of her research process by gathering data through qualitative interviews and transforming the findings of her research into poetic form. For the purposes of this paper an example of a specific arts-based narrative research method used by Casey (2009) will be described. This is a visual arts-based method (Imagework) developed by Edgar (2004).

Edgar's (2004) Imagework approach involves asking people to create a mental image that reflects the situation being considered. For example in healthcare contexts, participants, individually or in groups may be asked to visualise scenes or objects that are connected to experiences/narratives of being given a diagnosis or navigating a health issue. Articulation and exploration of these mental images are facilitated through asking the person to make an external picture or drawing of their 
mental image. The participant creates the picture or drawing of the mental image and subsequently describes the process of constructing their art piece and what they aimed to convey about their experiences. This session is recorded and transcribed and the completed images are photographed (with participant consent). Edgar (2004) provides a framework for analysis which focuses on the participants' stated process, meanings and subsequent personal or group responses regarding their created art narrative.

\section{Strengths and Challenges}

Jonas- Simpson et al. (2012) suggest that the strengths of using arts-based approaches lie in their capacity to enable articulation and analysis of previously under-explored, unvoiced narratives. Similarly, research audiences are drawn closer to the lived stories through this aesthetic evocation. With its focus on apprehending experience through divergent, aesthetic ways of knowing (Carper 1978, Leight 2002), arts-based research troubles relationships between knowledge and power and challenges traditional forms and institutionalized, habitual ways of thinking (Mitchell et al. 2011).

However, there are also some challenges in using these methods. Knowles \& Cole (2008) highlight that this work demands a high level of self-directed methodological rigour, creativity and innovation on the part of the researcher. Arts-based researchers are less likely to avail of 'off the shelf,' structured templates (Raingruber 2009), therefore Barone \& Eisner (2012) advocate that this research needs to be underpinned by a strong and continued awareness of the research questions/aims as well as ongoing reflexivity as to the selection and fit of particular arts methods. Researchers need to have ongoing sensitivity to ethical issues that arise in the field and issues of voice, representation and research purpose. The question of developing evaluative criteria to judge 
the merits, qualities and rigour of arts-based research has also provoked much debate with some researchers arguing that current qualitative research evaluation criteria are based in positivistic paradigms and are therefore not appropriate for arts-based research (Finlay 2011). However, scholars such as Finlay (2011), Lafrenière \& Cox (2013), Archibald et al. 2014) have worked at formulating criteria that reflect the aesthetic, methodological and ethical required standards for this work.

\section{Uses of Arts-based Narrative Approaches in health research}

Health care and the Arts have a common interest in narratives of the human condition. In nursing research, arts-based methods of inquiring and re-presenting are becoming more frequent, across a range of populations and contexts. Some examples include; the work of Mitchell et al. (2006) in creating a drama based on the experiences of living with dementia, Carter's \& Ford's (2013) examination of arts-based participatory approaches in researching children's health experiences and Casey's (2009) exploration of the identities and sense making processes of student nurses through their art-making. In Casey's (2009) study, arts-based participatory methods (poetry, visual art, drama, dance) enabled the exploration of the previously unvoiced narratives of student nurses, facilitated collaborative inquiry regarding some of the unquestioned assumptions adopted through the nursing socialization process and offered powerful ways of inquiring into student nurses' perceptions, motivations, biographies and identities as nurses and caregivers.

\section{Comparison of approaches}


When one considers the multiplicity of approaches that are used in narrative, Chase's (2005 p651) sentiment has clear resonance:

Contemporary narrative inquiry can be characterized as an amalgam of interdisciplinary analytic lenses, diverse disciplinary approaches and both traditional and innovative methods - all revolving around an interest in biographical particulars as narrated by one who lives them.

The approaches presented in this paper provide useful exemplars of the methodological amalgam that Chase refers to. Murray's framework, with its experience centered approach could be considered a more traditional narrative method whereas arts-based narrative approaches might be regarded as extending customary narrative approaches through innovative, creative practices. BNIM contributes to this diversity with its more structured focus on the narrated biographical particulars that Chase also alludes to. Accordingly, although all methods clearly share a narrative thread, there are nuanced differences in each in terms of particular narrative focus and interpretive lens. Table 1 provides an illustration summarizing the main components of each of these three approaches.

Table 1: Illustration of the main components of Murray's Narrative Framework, BNIM, and Arts-based Narrative Research 


\begin{tabular}{|c|c|c|c|}
\hline Characteristics & Murray's Narrative Framework & BNIM & Arts-based Narrative Research \\
\hline $\begin{array}{l}\text { Theoretical/ } \\
\text { Philosophical basis }\end{array}$ & $\begin{array}{l}\text { Phenomenology } \\
\text { Cognitive psychology } \\
\text { Social constructivism } \\
\text { Social constructionism }\end{array}$ & $\begin{array}{l}\text { Biographical methods } \\
\text { literary criticism/ linguistic analysis Social } \\
\text { constructionism } \\
\text { Grounded theory }\end{array}$ & $\begin{array}{l}\text { Phenomenology } \\
\text { Aesthetics } \\
\text { Social constructionism } \\
\text { Post structuralism }\end{array}$ \\
\hline Key contributors & Murray $(2000,2008)$ & $\begin{array}{l}\text { Fischer-Rosenthal and Rosenthal (1997), } \\
\text { Chamberlayne, Bornat and Wengraf (2000), } \\
\text { Wengraf (2001) }\end{array}$ & $\begin{array}{l}\text { Edgar (2004), Knowles and Cole (2008), Leavy } \\
\text { (2009), Barone and Eisner (2012) }\end{array}$ \\
\hline $\begin{array}{l}\text { Methodology/ } \\
\text { Methods of data collection } \\
\text { and analysis }\end{array}$ & Semi-Structured interview & $\begin{array}{l}\text { Initial unstructured interview (single question } \\
\text { aimed at inducing narrative (SQUIN) - } \\
\text { followed by semi structured follow up. } \\
10 \text { stage formula ( } 9 \text { on individual case and } 10^{\text {th }} \\
\text { stage cross-case comparison) } \\
\text { Interpretive panels used ( } 3 \text { panels per case) }\end{array}$ & $\begin{array}{l}\text { Participants facilitated to create art (individual } \\
\text { or group) based on area of inquiry or more } \\
\text { traditional data collection method used and } \\
\text { data analysed and translated into art form } \\
\text { Visual analysis of visual art/photographs, } \\
\text { narrative analysis of language based data and } \\
\text { contextual discussions. Analysis may be } \\
\text { researcher led/participatory }\end{array}$ \\
\hline Strengths & $\begin{array}{l}\text { In-depth exploration of personal lived } \\
\text { experience as created and recounted } \\
\text { through narrative } \\
\text { Hermeneutic analysis using } 4 \text { 'lenses' } \\
\text { allows for the understanding of health and } \\
\text { illness experiences from different } \\
\text { perspectives }\end{array}$ & $\begin{array}{l}\text { Facilitates understanding of individual life story } \\
\text { within historical and cultural context through } \\
\text { multi-level analysis of biography, lived life, told } \\
\text { story. } \\
\text { Provides clear and rigorous structure to } \\
\text { intensively analyse life stories from a small } \\
\text { cohort of participants. }\end{array}$ & $\begin{array}{l}\text { Goes beyond limits of familiar language usage, } \\
\text { facilitates previously 'unvoiced' narratives, } \\
\text { challenges meta-narratives. } \\
\text { Participatory, Embodied, Evocative }\end{array}$ \\
\hline Challenges & 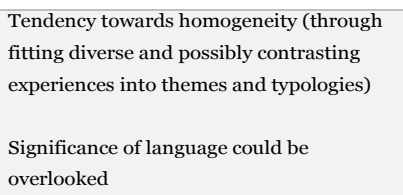 & $\begin{array}{l}\text { Formulaic - can decontextualize narratives by } \\
\text { ignoring interactional / power/situational } \\
\text { factors in narrative production and sharing } \\
\text { Risk of over complex data generation }\end{array}$ & $\begin{array}{l}\text { Difficulty in establishing agreed evaluative } \\
\text { criteria to judge the merits, qualities and rigour } \\
\text { of arts-based narrative research } \\
\text { High level of self-directed research ethics, } \\
\text { rigour and innovation required }\end{array}$ \\
\hline $\begin{array}{l}\text { Examples of use in health } \\
\text { research }\end{array}$ & $\begin{array}{l}\text { Murray (2009), Mc Mahon et al (2012), } \\
\text { Proudfoot (2014) }\end{array}$ & $\begin{array}{l}\text { O’Neill 2011, Corbally (2011), Nicholson et al } \\
\text { (2013), Garrat (2014) }\end{array}$ & $\begin{array}{l}\text { Casey (2009), Boydell (2011), Carter and Ford } \\
\text { (2013) }\end{array}$ \\
\hline
\end{tabular}

Rarely is a research method developed from a unitary epistemological base and the above table illustrates how similar and diverse epistemological positions can influence the development of novel research methods. The fact that social constructionism is a shared assumption among all three illustrates a commonality across these narrative approaches. Equally, elements of diversity and uniqueness are apparent, for example in the varying emphasis on realism and social construction between the approaches as well as variations in methodological practice in data collection, analytic techniques and representation of findings.

\section{Implications for nursing; how can understanding of narrative research methods enhance} nursing research and practice? 
For nurses considering narrative approaches in research/ to enhance understanding in nursing practice, the decision as to which narrative method one adopts can be complex and needs to be informed by the research question, research/practice context and the affordances and constraints / limits of each method. One way to explain this is to consider how each narrative approach might be used to explore, for example, stories of chronic pain. A researcher/inquirer adopting Murray's method to explore chronic pain for instance will be interested in the personal experiential account of pain, the metaphors and language the person uses to describe their pain, the person's social story and the part that pain plays in that context. This approach is useful if the researcher wishes to consider the lived experience of pain and its influence in the person's wider lived context. Additionally, the researcher recognises the part that s/he plays as audience to that account and will engage in a reflexive process considering the interpersonal and positional relations between researcher and researched; in this case possible power differentials and the researcher's own experiences and attitudes concerning pain.

A nurse researcher using BNIM, to explore chronic pain narratives will be interested to a greater extent in how this story has been constructed and shaped over time and context through tellings and re-tellings. For example, in this case, how at different times the narrator may present self as a victim of chronic pain or as a survivor. The researcher will also be interested in the dynamics between the story as told and the actual lived experiences of the narrator and the analysis will systematically focus on uncovering some of these dynamics. Generating insights into the differences between lived lives and told stories is of great benefit to nursing interactions and interventions given that nursing work involves the appreciation of complexity and ambivalence in peoples' perceptions and responses. 
Arts-based narrative approaches might be used in the exploration of the physically embodied experience of chronic pain. An arts-based inquirer may argue that conventional words are not sufficient or possible to express the pain narrative therefore painting, dance or poetic form might facilitate this articulation and bring the audience/viewer closer to the actual experience. The artmaking process may also enable the researcher to uncover/discuss other experiences related to the pain narrative for example body image, body agency, treatment, impact of surrounding cultural attitudes to pain. These concerns can be discerned through the choice of metaphors or composition of the art piece.

It is clear that while there are philosophical, interpretive and analytical variations, all three approaches work to generate insights about the stories people tell concerning their lived experience. The insights achieved are nuanced and informed by the approach taken.

\section{CONCLUSION}

Using narrative processes to configure life experiences, particularly those of trauma or illness is an essential human sense making activity. Implicit in nursing work worldwide, is the interpretation of these stories by practitioners who use patients' accounts to gain understanding of the subjective illness experience and to determine care. The conduct of nursing and narrative inquiry are inextricably linked as both are concerned with interpreting stories told to practitioners. Many contemporary nurse researchers argue that the sharing and exploration of narratives reveal phenomenological and socio-cultural insights which in turn contribute to the development of nursing/healthcare knowledge and research practice (Chan et al. 2013). 
As outlined in this paper, narrative research encompasses a range of approaches which take as their central focus the construction, articulation and interpretation of storied accounts. However, each approach will provide a slightly different lens on the story under inquiry and the modes of accessing, exploring and re-presenting these stories may differ depending on which approach is adopted. The complexity of contemporary research contexts, particularly those involving experiences of illness and distress, demands research approaches that 'catch and care for the sparkle of moments of beauty, of reverence, of joy or personal pain' (Mair $1989 \mathrm{p} 63$ ). The choice of approach will depend on the research questions and the unique characteristics of the research context. Consequently, the three narrative approaches presented in this paper confirm the usefulness and richness of this research methodology for nurse researchers wishing to inquire into the storied nature of human experience and sense making. 


\section{References}

Adamski M., Parsons V., \& Hooper C. (2009) Internalizing the concept of caring: An examination of student perceptions when nurses share their stories. Nursing Education Perspectives 30(6), 358361.

Archibald M., Caine V., \& Scott S.D. (2014) The development of a classification schema for artsbased approaches to knowledge translation. Worldviews on Evidence Based Nursing 11(5), 316324 .

Atkinson P. \& Silverman, D. (1997). Kundera's Immorality: The Interview Society and the Invention of Self. Qualitative Inquiry, 3(3), 324-345.

Casey B. (2009) Arts-based inquiry in nurse education. Contemporary Nurse 32(1-2), 69-82.

Casey B. \& Gordon E. (2010) Interpreting and responding to expressions of mental pain: The inner and outer dialogues of the mental health nurse. In: Nursing Issues: Psychiatric Nursing, Geriatric Nursing and Nursing Burnout (Mclaughlin C. \& Docherty J. eds.), Nova Publishers, New York pp. $171-191$.

Proudfoot D. (2014) A narrative exploration into the experiences of mothers living with HIV in Ireland. Unpublished thesis for Professional Doctorate in Health, Department of Health, University of Bath.UK.

Corbally M. (2011) Making Sense of the Unbelievable: A Biographic Narrative Study of Men's Stories of Female Abuse. DProf. Health and Social Care, University of Salford.

Corbally M. \& O'Neill C.S. (2014) An Introduction to the Biographical Narrative Interpretive Method. Nurse Researcher 21(5), 34-39.

Barone T. \& Eisner E. W. (2012) Arts-based research. Sage, London.

Berger P.L. \& Luckman T. (1966) The Social Construction of Reality. Irvington Publishers, New York.

Blumenreich M. (2004) Avoiding the pitfalls of 'conventional' narrative research: using poststructural theory to guide the creation of narratives of children with HIV Qualitative Research, 4(1), 77-90. 
Bornat J. 2008. Biographical Methods. In The SAGE Handbook of Social Research Methods (Alasuutari P., Bickman L. \&. Brannen J. eds.), Sage London, pp. 344-356.

Bruner J. (1990) Acts of Meaning (the Jerusalem-Harvard Lectures), Harvard University Press, Cambridge, Mass.

Calvert D. (2014) 'A person with some sort of learning disability': the aetiological narrative and public construction of Susan Boyle. Disability \& Society, 29(1), 101-14.

Carolan M. (2005) The role of stories in understanding life events: poststructural construction of the 'self'. Collegian, 12(3), 5-8.

Carper B. (1978) Fundamental Patterns of Knowing in Nursing. Advances in Nursing Science 1(1), $13-24$.

Carter B. \& Ford K. (2013) Researching children's health experiences: The place for participatory, child-centered, arts-based approaches. Research in Nursing \& Health 36(1), 95-107.

Chamberlayne P., Bornat J. \& Wengraf T. (2000) The Turn to Biographical Methods in Social Science. Routledge, London.

Chan E.A., Jones A. \& Wong K. (2013) The relationships between communication, care and time are intertwined: a narrative inquiry exploring the impact of time on registered nurses' work. Journal of Advanced Nursing 69(9), 2020-2029.

Chase S. (2005) Narrative inquiry, multiple lenses, approaches, voices. In The Sage Handbook of Qualitative Research $3^{\text {rd }}$ ed. (Denzin N. \& Lincoln Y. (eds.), Sage, Thousand Oaks, CA pp. 651-679

Dewey J. (1934) Art as Experience Putnam, New York

Edgar I.R. (2004) Guide to Imagework: Imagination-Based Research Methods. Routledge, London.

Edwards S.L. (2015)Transforming the findings of narrative research into poetry. Nurse Researcher, 22(5), 35-9.

Finley S. (2011) Critical arts-based inquiry. The Pedagogy and Performance of a Radical Ethical Aesthetic. In The Sage Handbook of Qualitative Research 4th ed (Denzin N. \& Lincoln Y. (eds.), Sage, Thousand Oaks, CA pp. 435-450). 
NARRATIVE IN NURSING RESEARCH: AN OVERVIEW OF THREE APPROACHES

Foucault M. (1972/1969) The archaeology of knowledge. New York, Pantheon Books.

Foucault M. (1980) Power/knowledge: selected interviews and other writings 19721977 Pantheon Books, New York.

Frank A. (1995) The wounded storyteller: body, illness and ethics. University of Chicago Press, Chicago.

Frosh S. (2004) Knowing more than we can say. In Collaborative Practice in Psychology and Therapy. (Pare D. A. \& Larner G. eds.), Haworth Press, New York. pp. 55-68.

Gadamer H. (1989) Truth and Method (trans. Weinsheimer J Marshall D.), Crossroad, New York.

Garratt R. (2014) Connecting with women: the working lives of independent midwives and their perceptions of the mother-midwife relationship. PhD Thesis De Montfort University (United Kingdom).

Glaser B.G. \& Strauss A. (1968) The Discovery of Grounded Theory. Weidenfeld and Nicholson, London.

Gregen ‥ (2009) An Invitation to Social Construction. Sage, Los Angeles.

Gergen, M. M. \& Gergen K. J. (2012) Playing with purpose: Adventures in performative social science. Left Coast Press, Walnut Creek, CA.

Gregory S. (2010) Narrative approaches to healthcare research. International Journal of Therapy \& Rehabilitation 17(12), 630-636.

Gubrium, J. \& Holstein J. (2009) Analyzing narrative reality. London, England, Sage.

Gunaratnam Y. \& Oliviere D. (eds.) (2009) Narrative and Stories in Health Care: Illness, Dying and Bereavement. Oxford University Press, Oxford.

Holloway I. \& Freshwater D. (2007) Narrative Research in Nursing. Blackwell, Oxford.

Jonas-Simpson C., Mitchell G.J., Carson J., Whyte C., Dupuis S. \& Gillies J. (2012)

Phenomenological shifts for healthcare professionals after experiencing a research-based drama on living with dementia. Journal of Advanced Nursing 68(9), 1944-1955. 
Jones K. (2001) Narratives of Identity and the Informal Care Role. PhD edn, De Montfort University, De Montfort University.

Jones K. (2003) The turn to a narrative knowing of persons: One method explored. Nursing Times Research 8, 60-71.

Knowles G. \& Cole A. (2008) Handbook of the Arts in Qualitative Research: Perspectives, Methodologies, Examples and Issues. Sage, Thousand Oaks CA

Labov W. \& Waletzky J. (1967/1997). Narrative analysis: Oral versions of personal experience. Journal of Narrative and Life History, 7(1-4), 3-38.

Lafrenière D. \& Cox S. (2013) 'If you can call it a poem': toward a framework for the assessment of arts-based works. Qualitative Research. 13, 318-336.

Lapum J., Hamzavi N., Veljkovic K., Mohamed Z., Pettinato A., Silver S. \&Taylor E. (2012) $\underline{A}$ performative and poetical narrative of critical social theory in nursing education: an ending and threshold of social justice. Nursing Philosophy. 13(1), 27-45.

Lapum J., Yau T., Church K., Ruttonsha P. \& Matthews D. A. (2013) Un-earthing emotions through art: reflective practice using poetry and photographic imagery. Journal of Medical Humanities, Available at http://www.ncbi.nlm.nih.gov/pubmed/24122299 (accessed 14 ${ }^{\text {th }}$ March 2015).

Law B., Yee-Shui., C \& Engle A. (2015) The experience of learning to speak up: a narrative inquiry on newly graduated registered nurses. Journal of Clinical Nursing, 24 (13/14), 1837-48.

Leavy P. (2009) Method meets art: Arts-based research practice. The Guilford Press, New York. Leight S. B. (2002) Starry night: Using story to inform aesthetic knowing in women's health nursing. Journal of Advanced Nursing 37(1), 108-114.

Leitch R. (2006) Limitations of language: developing arts-based creative narrative in stories of teachers' identities. Teachers and Teaching: Theory and Practice 12(5), 549-569.

Lomas C. (2012) The burden of bureaucracy. Nursing Standard, 26(30), 22-24.

MacLellan J. (2015) Healing identity by telling childbirth stories on the internet. British Journal of Midwifery, 23(7), 477-82 
Mair M. (1989) Between Psychology and Psychotherapy: A Poetics of Experience. Routledge, London.

Mc Allister M., John T., Gray M., Williams L., Barnes M., Allan J. \& Rowe J. (2009). Adopting narrative pedagogy to improve the student experience in a regional Australian University. Contemporary Nurse 32(1-2), 156-165.

Mc Cance T.V., McKenna H.P. \& Boore J.R.P. (2001) Exploring caring using narrative methodology: an analysis of the approach. Journal of Advanced Nursing 33(3), 350-6.

Mc Mahon L., Murray C., \& Simpson J. (2012) The potential benefits of applying a narrative analytic approach for understanding the experiences of fibromyalgia: a review. Disability and Rehabilitation 34(13), 1121-1130.

Meares C. (2007) From the Rainbow Nation to the Land of the Long White Cloud: Migration, Gender and Biography, PhD thesis, Massey University, New Zealand.

Merleau-Ponty M. (1999) Phenomenology of Perception [translation]. Rutledge Publishers, New York, NY.

Mitchell G. J., Jonas-Simpson C. \& Ivonoffski V. (2006) Research-Based Theatre: The Making of I’m Still Here! Nursing Science Quarterly. 19,198-206.

Mitchell G. J., Dupuis S., \& Jonas-Simpson C. (2011) Countering stigma with understanding: The role of theatre in social change and transformation. Canadian Theatre Review, 146(1), 22-27.

Murray M. (2000) Levels of narrative analysis in health psychology. Journal of Health Psychology, 5(3), 337 .

Murray M. (2008) Narrative psychology In Qualitative psychology: a practical guide to research methods (Smith, J.A. ed.), Sage, London, pp.111-132.

Murray M. (2009) Telling stories and making sense of cancer. International Journal of Narrative Practice 1, 25- 36.

Nicholson C., Meyer J., Flatley M. \& Holman C. (2013) The experience of living at home with frailty in old age: A psychosocial qualitative study. International Journal of Nursing Studies 50(9), 11721179. 
O'Neill C.S. (2011) Ethical Decision Making in Care of Older People: An Ethnography of Treatment Decisions in Irish Hospitals. PhD thesis, University College Dublin, Dublin.

Ofri D. (2015) Patient Health Literacy, Electronic Health Records and other Challenges of Modern Medicine. Generations 39 (1), 83-7.

Overcash J. (2004) Using Narrative Research to Understand the Quality of Life of Older Women With Breast Cancer. Oncology Nursing Forum 31(6), 1153 -1159

Patterson W. (2008) Narratives of events: Labovian event analysis and its limitations. In Doing Narrative Research (Andrews M., Squire C. \& Tamboukou M. eds), Sage, London, pp 22-40.

Raingruber B. (2009) Assigning poetry reading as a way of introducing students to qualitative data analysis. Journal of Advanced Nursing 65(8), 1753-1761.

Ramvi E. (2015) 'I am only a nurse': a biographical narrative study of a nurse's selfunderstanding and its implication for practice. BMC Nursing, 2015; 14(1), 1-9.

Riessman C.K. (2008) Narrative methods for the human sciences. Sage, London.

Rogers A.G. (2007) The unsayable, Lacanian psychoanalysis and the art of narrative interviewing. In Handbook of Narrative Inquiry: Mapping a Methodology (Clandinin D.J., ed.), Sage, Thousand Oaks, CA, pp. 99-119.

Sandelowski M. (1994) We are the stories we tell: narrative knowing in nursing practice. Journal of Holistic Nursing 12(1), 23-33.

Sarbin T.R. (ed.)(1986), Narrative Psychology: The Storied Nature of Human Conduct, Praeger Press, London.

Schick Makaroff L., Sheilds L. \& Molzahn A. (201 3) Stories of chronic kidney disease: listening for the unsayable. Journal of Advanced Nursing 69(12), 2644-2653

Shelton N. \& Johnson S. (2006) 'I think motherhood for me was a bit like a double-edged sword': the narratives of older mothers. Journal of Community \& Applied Social Psychology 16(4), 316330. 
Sparkes A. C., \& Smith B. (2008) Narrative Constructionist Inquiry In Handbook of Constructionist Research (Holstein J.A. \& Gubrium J.F. eds.), Guildford Press, New York, pp. 295 - 315.

Squire C. (2008) Approaches to Narrative Research. ESRC National Centre for Research Methods Review Paper. Available at http://eprints.ncrm.ac.uk/419/1/MethodsReviewPaperNCRM-oo9.pdf (accessed 14th March 2015)

Stickley T., Hui A., Morgan J., Bertram G. (2007) Experiences and constructions of art: a narrative-discourse analysis. Journal of Psychiatric \& Mental Health Nursing 14(8), 783-90

Taylor C. (2003) Narrating practice: reflective accounts and the textual construction of reality. Journal of Advanced Nursing 42(3), 244-51

Vallido T., Wilkes L., Carter B. \& Jackson D. (2010) Mothering disrupted by illness: a narrative synthesis of qualitative research. Journal of Advanced Nursing 66(7), 1435-1445.

Van Manen M. (1997) Researching the Lived Experience: Human Science for an Action Sensitive Pedagogy. The Althouse Press, London, Ontario.

Vygotsky L. (1978) Mind in Society. Harvard University Press, London.

Wengraf T. (2001) Qualitative Research Interviewing - Biographic Narrative and SemiStructured Methods. Sage, London.

Wengraf T. (2008) Life-histories, lived situations and ongoing personal experiencing using the Biographic-Narrative Interpretive Method (BNIM). Guide to BNIM interviewing and interpretation. Available at http://www.methodspace.com/profile/TomWengraf (accessed 12th March 2015).

White M. (2004) Working with People Who Are Suffering the Consequences of Multiple Trauma: A Narrative Perspective. International Journal of Narrative Therapy \& Community Work 1, 45-76.

Williams S.L. (2009) Recovering from the psychological impact of intensive care: how constructing a story helps. Nursing in Critical Care. 14(6), 281-8.

Wilson L. \& Crowe M. (2009) Parenting with a diagnosis bipolar disorder. Journal of Advanced Nursing 65(4), 877-84.

Wolf Z. R. (2008) Nurses' stories: discovering essential nursing. Medical Surgical Nursing, 17(5), $324-329$. 
NARRATIVE IN NURSING RESEARCH: AN OVERVIEW OF THREE APPROACHES

Wright D. J. (2006) The art of nursing expressed in poetry. The Journal of Nursing Education 45(11), 458-461. 